\title{
A Study of Key Factors Influencing Youth Voter Turnout
}

\author{
Claire Zhu \\ California, USA, June 2021
}

\begin{abstract}
Youth voters between 18 and 29 years of age have consistently had the lowest turnout among all age groups in U.S. elections. This research analyzed from a youth perspective the major factors that are known to impact general voter turnout to determine their distinct influence, or lack thereof, on young voters. The key findings, detailed in this paper, are

- The commonly known factors that impact general population's voting participation have a markedly different level of influence on the current and future voters from their pre-voting-eligible ages to late twenties.

- Race and ethnicity, social media, geography, income, and education are among the weightier factors that affect young voters' decisions to vote.

The outcome of this research lays the foundation for a study on a youth engagement framework consisting of specific strategies and actionable tactics to significantly boost their voting rates.
\end{abstract}

\section{KEYWORDS}

Youth voter turnout; Factors; Race and Ethnicity; Social Media; Geography; Income; Education

\section{INTRODUCTION}

\section{A. Background and Objective}

As the 2020 election is now behind us, a new 4-year presidential election cycle starts. There are many factors that will sway the voters and affect the next election's results: politics, economy, society, technology, healthcare, and others. Over the past half century, much research has been conducted to study the impact of these factors on modern era elections, and the outcomes of these studies have played important roles in candidates' and political parties' campaign strategies. 
In the end, however, it all comes down to the voters. With the Census Bureau data of the presidential elections from 1980 to $2016^{[-1-1]}$, Diagram I-A-1 illustrates that younger Americans, i.e. 18- to 29-year olds, always had much lower voting rates when compared to older age groups, hence making them a much less influential population on the nation's political stage.

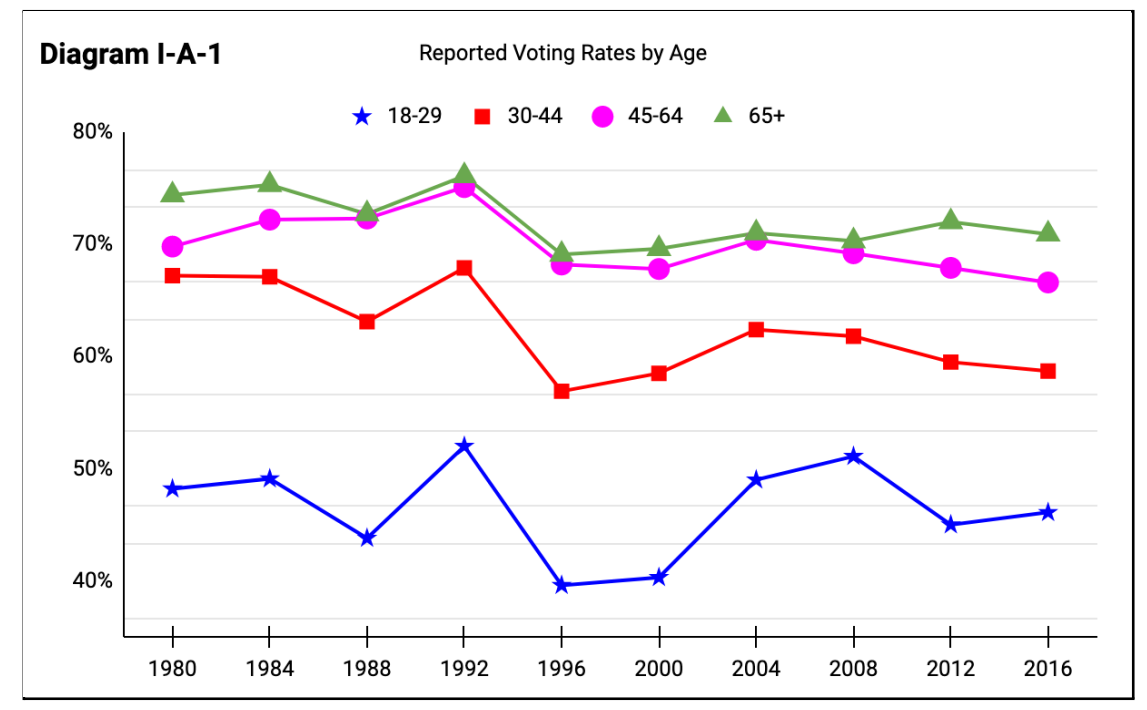

In recent decades, the 18 - to 29 -year-old age group has had 50 million or so eligible voters. While that accounts for about $20 \%$ of all legal voters, the role they play in presidential elections is considerably less than that of other age groups.

The objective of this research was to identify the factors that impact young voter participation, in order to enable a follow-up study that establishes a framework for meaningfully engaging the youth starting from their pre-voting-eligible ages and encouraging them to vote.

\section{B. Methodology and Approach}

This is a research on developing youth interest in the most fundamental democratic process, and the intricacies involved in doing so. It studied the factors that influence youth voter engagement, with the following approaches:

- Emphasizing using a youth perspective throughout the process

- Starting with major factors that are known to impact general voter turnout to assess and distinguish their level of effect on young voters specifically 
- Focusing on factors that pertain to voters' personal characteristics or within voters' own discretions

With that, the results of the research presented unique academic and practical values.

\section{Value and Use}

Youth before and even after becoming eligible to vote are at a stage in their lives when they are figuring out their political identities and stances. Paying specific attention to the factors identified in this research that have the most sway on young voters, candidates, political parties, and civic groups can make an informed decision on how to most optimally engage youth in order to achieve their goals in elections.

\section{STUDY OF YOUTH TURNOUT}

\section{A. Understanding Voter Turnout}

Having established that young voters can meaningfully impact the election results (detailed in a separate paper, “A Data-Driven Analysis of Youth Turnout Impact on U.S. Presidential Elections”), the next step is to study how to boost their actual engagement levels. In order to develop effective approaches for motivating this age group, it is important to first understand the factors that influence their turnout.

There have been plenty of studies on voter turnout. This research, however, focused specifically on youth from their pre-voting-eligible ages to late twenties.

The following chart illustrates the impact level of the key factors that are commonly known to affect general voter turnout, and, based on this research, how they are relevant to the current and future young voters. Factors such as electoral competitiveness, election types, candidates, bills on the ballot, and election day weather were not visited in this research, as they do not pertain to voters' personal characteristics or within voters' own discretions. There were researchers that studied these factors in depth, for example, "Turnout and Weather Disruptions: Survey Evidence from the 2012 Presidential Elections in the Aftermath of Hurricane Sandy." by Professor Robert Shapiro, Narayani Lasala-Blanco and Viviana Rivera-Burgos ${ }^{[\mathrm{II}-1]}$. 


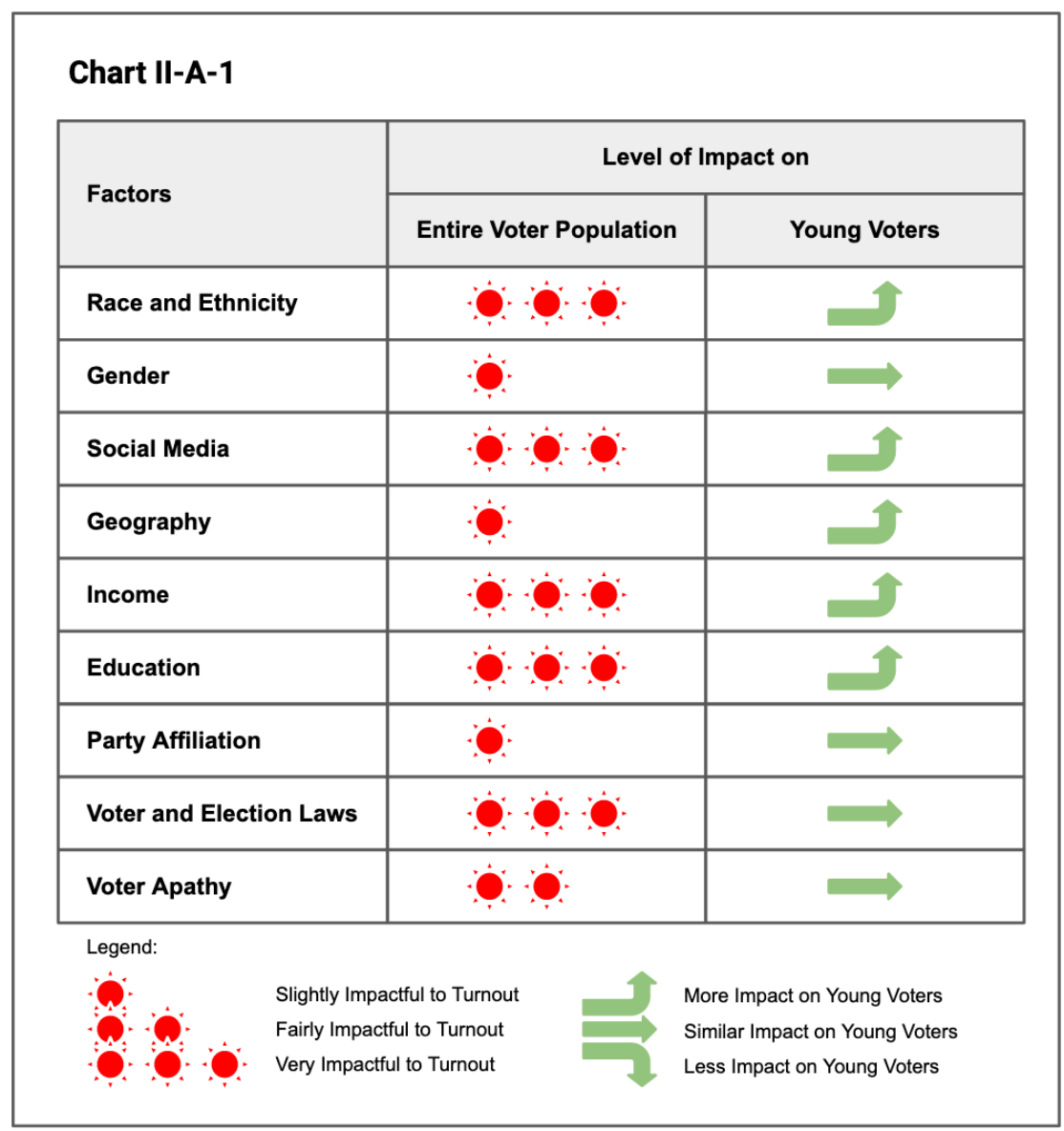

\section{B. Factors Impacting Youth Turnout}

Detailed analysis of the factors in the above chart are discussed below.

\section{Race and Ethnicity}

Over the recent decades, election data finds that:

- Voter participation among some minority groups including Hispanics and Asians has increased slightly, while that of black and white people are fluctuating in a small range.

- Nationwide, the gap of voting rates between white and black people is narrowing.

- In places where minority groups have a more decisive influence on the election outcomes, with a higher population of minorities, the turnout disparity is smaller between different races and ethnicities.

- Overall, there is still a significant gap in voter participation between the group of white and black 
people and the rest population.

Diagram II-B-1 below, based on data from a Statista publication ${ }^{[\mathrm{II}-2]}$, shows the varied voting rates and their trending among several selected race and ethnicity groups. It is evident that the race and ethnicity impact on voter turnout is substantial. While the finding pertains to the entire voting population, it is even more relevant to the youth group as the recent generations are getting more and more diverse.

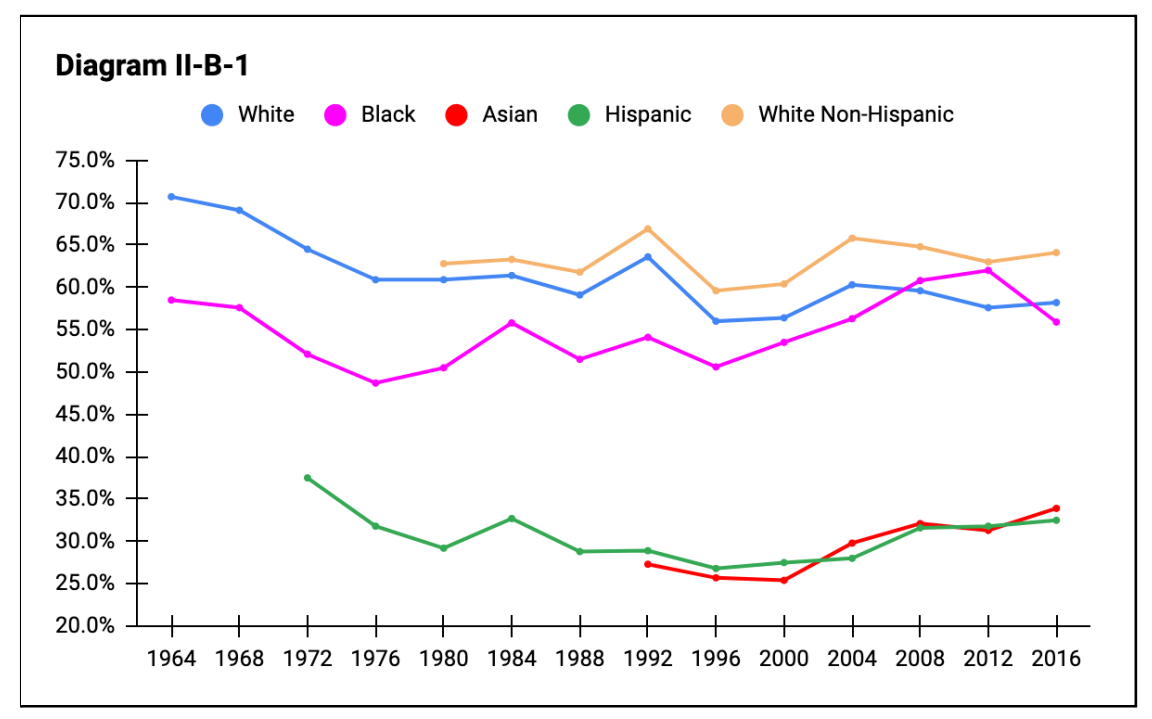

\section{Gender}

Other than race and ethnicity, voter participation and political engagement are affected by several other voter demographics, such as gender. Women are more likely to vote and considered quietly active, while men are generally more outspoken about politics through direct contact and in groups but slightly less likely to take action in elections. This is partly attributed to that women, who are oftentimes the primary caregivers in typical households in this country, are more involved with matters in daily life that have to do with government policies and social issues, such as education, healthcare, housing, home security, and social welfare.

However, data shows that the gender difference in voter turnout is relatively small, which is quite different from its strong influence on voter choice, party affliction, and policy preference. According to an article published by Pew Research Center ${ }^{[I-3]}$, the voting rates between male and female have been 4 points or less apart since the 1980 presidential election. For example, in 2016, 63\% of women who were 
eligible voters said they cast ballots, compared with $59 \%$ of men. Therefore, gender as a factor has just a slight impact on general voter turnout, which is likely the same case for the youth population as well.

\section{Social Media}

Social media is an increasingly widespread and wide-reaching technology platform, and it allows people to gather and share opinions on politics, among other topics, as well as to attack opposing views. It is believed that social media platforms could have a hand in growing political polarization. The use of social media not only widens the audience and the scope of the election, but also lets people feel more comfortable fighting and arguing with others virtually as opposed to in person. As a result, social media platforms provide a way for people to become more contrasted and increasingly contentious. Although this can often be toxic and destructive, it can spur people emotionally into action and going out to vote.

According to the results of a randomized controlled trial of political messages on Facebook ${ }^{[I-4]}$, the social network platform is believed to be effective in online political mobilization and, subsequently, lifting voter turnout in the elections. Since around 2010, more and more politicians, civic groups, and government organizations have started to use digital strategies to campaign for their causes, hoping to energize their bases to show up in elections.

Social media is already common in current society, but it is notably more prevalent in young people's lives. With much higher access to and more time spent on social network apps by the current and future young voters, social media will just become a substantially more impactful factor to voter turnout.

Up until the turn of the 21 st century, traditional media was one of the most used tools in reaching out to voters. As quoted in an article by BBC political reporter Gavin Stamp ${ }^{[\mathrm{II}-5]}$, in an April 2010 survey conducted by Opinion Matters, television, newspaper and radio were ranked the top three voter influencers. There is still a considerable amount of political campaign spending in these forms of traditional media. However, nowadays, the ability to reach young voters via these platforms is essentially very limited. As the current youth eventually grow to be a major portion of the voting population in the next several decades, social media may become as common in political activities as traditional media, if 
not more.

\section{Geography}

Geographically, there's no significant correlation between voter turnout and voter location. While northern states are slightly more politically engaged than southern ones, and coastal states are more engaged than inland states, there is lack of clear evidence that geography itself has much to do with how actively people vote in elections.

However, when considered as a factor for youth voter turnout, geography becomes a bit more relevant. According to the data released by the Census Bureaus on April 18, 2019[I-6], the nation's population growth is uneven, with the counties in the South and West taking a clear lead over others, and the fastest growing metropolitan areas are not the most populous ones in the country. In the same release, it also indicates that the growth is contributed to by both natural increase and migration, both of which will lead to a greater number of young voters in the next several decades.

These trends of uneven population growth in different parts of the country will likely, in the years to come, make geography a driving factor in establishing location specific voter engagement programs that target young voters.

\section{Income}

Income, a key component of socioeconomic status, has been well studied and documented for its relation to voter turnout, and the result is that there is a positive and clear association between higher family incomes and greater voter turnout. According to the Census Bureau data ${ }^{[I-7]}$ from November 2016, only $41.4 \%$ of citizens with family incomes of under $\$ 10,000$ voted. In comparison, $80.3 \%$ of those with family incomes of $\$ 150,000$ or more voted. Based on a correlation analysis published by Adam McCann from WalletHub ${ }^{[I I-8]}$, there is also a positive correlation between GDP per capita and voter participation: the higher the GDP per capita of the state, the higher the political engagement of that state. In simple terms, the level of wealth of the individuals and the individuals' community is clearly a factor influencing how likely they will vote. 
As most young voters are still in school or just entering the workforce, many belong to the lower income groups. This factor could be a major one that contributes to the low turnout of this age group.

\section{Education}

Another key component of one's socioeconomic status is education. As illustrated in Diagram II-B-2 using data from the Census Bureau ${ }^{[I I-9]}$, voter turnout increases consistently and significantly as the voter's level of education goes up. Another apparent trend shown by the diagram is that, in recent years, while the participation rate is generally on a downward trajectory across all education levels, lesser educated groups lose interest in the democratic process more than the other groups. Therefore, as this trend is likely to continue, which increases voting rate disparity, education level can be considered a stronger factor impacting voter turnout of the future generations.

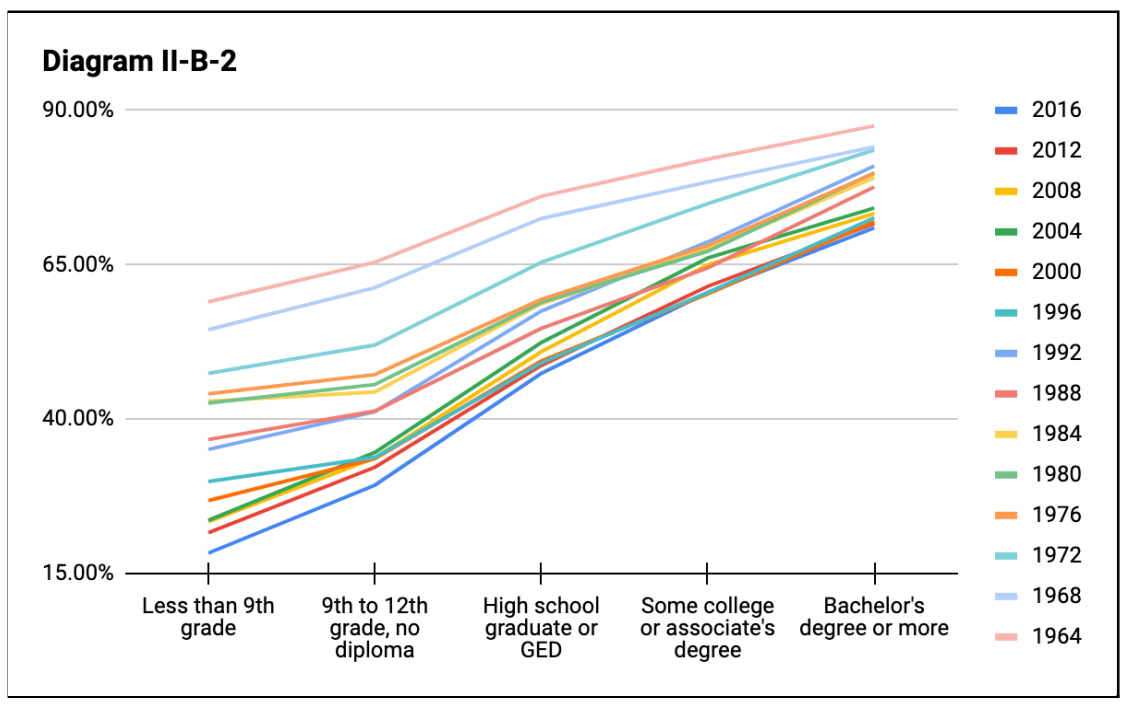

\section{Party Affiliation}

While data shows that blue states are more politically involved than red states, there has not been clear evidence that Democrats are more likely to vote than Republicans, or the other way around. Although the mere factor of association with one political party or another doesn't mean increased or decreased voter participation, it does look like that certain values advocated by the party may correspond with stronger political opinions. If any of such opinions is at stake in an election, higher turnout of the party members is likely. For example, relating to education, a Pew Research Center article ${ }^{[\mathrm{II}-10]}$ states that "The share of 
Americans saying colleges and universities have a negative effect has increased by 12 percentage points since 2012. The increase in negative views has come almost entirely from Republicans and independents who lean Republican.” It indicates that Republicans are growing more negative towards higher education, while Democrats have not changed their opinion much. This could lead to different levels of political engagement between parties on education, or other topics that one political alignment may prioritize over another.

Where the younger generation is considered, their party affiliation itself will similarly not make them more or less likely to cast ballots. However, certain values or concerns specific to these parties as election topics or voting issues will incentivize them to vote more actively.

\section{Voter and Election Laws}

According to a calculation by Pew Research Center ${ }^{[I I-11]}$ using data from International Institute for Democracy and Electoral Assistance and various national election authorities, the U.S. voting age population turnout is ranked 30th out of 35 OECD nations for which data is available. Among youth participation, the U.S. is also among the lowest of developed countries. Along with factors mentioned above, voter and election laws have a big part in it.

The laws are complex, which can be alienating to younger voters. Although laws' intricacies may be necessary, there is a lack of formal education and informal information-sharing of their specifics for many Americans. As a result, younger people, more so than their older counterparts, are unsure or confused about how to vote in major elections, or even how to participate in state or regional elections. This can be off-putting for youth who are starting to figure out their lives and futures.

Additionally, laws have made the voting process more troublesome and inconvenient. For example, voter registration is required in almost all states, and the U.S. is one of the few countries that make registration a separate event from voting. While some states allow election day registration, two thirds of the country has cutoff dates for registration or registration updates, typically two to four weeks ahead of election. Whereas for South Korean citizens, for example, there is no formal process for registering to 
vote, as they are automatically listed in the voters' list for each election when they come of age. Also, in many states, voter registration means being eligible and obligated for jury duty. It has been seen that not a small amount of lower income families forgo registration in order to avoid jury duty, because they can't afford to miss work. In addition, in the U.S., elections are held on weekdays, effectively discouraging voters to participate when they might have work or school.

With different political purposes, changes go into election laws all the time, which brings multiple potential concerns:

- Frequent changes make complex matters even harder to keep up-to-date with.

- Some changes can even be counterproductive in the quest of increasing voter participation. For example, according to a study ${ }^{[\mathrm{II}-12]}$ published by the American Journal of Political Science, "The most popular reform-early voting-is actually associated with lower turnout when it is implemented by itself," and result of the study "upends the conventional view that anything that makes voting easier will raise turnout."

- Some time, the nature of the changes to election laws can be controversial as well, such as with concerns about voter suppression.

Also in comparison with other countries, American laws are becoming obsolete. Other countries with higher voter turnout not only have voter laws like automatic registration but also compulsory voting, and have even started studying roles of current technology in the political process, including online voting.

Voter and election laws will continue to be a big factor influencing the turnout of the younger generations.

\section{Voter Apathy}

Voter apathy is often the cause of low voter turnout. Typical reasons why voters choose not to vote are:

- No faith in the candidates or elected officials

- Seeing lack of competitiveness in the election

- Being tired of too frequent elections 
- Not regarding politics as relevant to their lives

- Believing there is corruption in the voting process or the government

- Experiencing political alienation

In the U.S., many non-voters cite multiple of the above as reasons for not voting. Although current young voters may experience some of these factors to lesser of an effect than older generations, such as being tired of too frequent elections, many of the others definitely hold true and may be to a slightly greater extent for them.

\section{CONCLUSION}

The outcomes of this research, which are the key factors that were found to have significant influence on youth voter participation, provided the foundation for the study and development of an effective engagement framework that would fundamentally improve current and future youth voter turnout in the elections (detailed in a separate paper, “A Study for Improving Youth Voter Participation”). 


\section{REFERENCES}

[I-1] File, Thom. "Voting in America: A Look at the 2016 Presidential Election". United States Census Bureau. 10 March 2017.

https://www.census.gov/newsroom/blogs/random-samplings/2017/05/voting_in_america.html

[II-1] Lasala-Blanco, Narayani, Shapiro, Robert Y., Rivera-Burgos, Viviana. "Turnout and weather disruptions: Survey evidence from the 2012 presidential elections in the aftermath of Hurricane Sandy”. Electoral Studies, Volume 45, 141-152. 2017.

https://doi.org/10.1016/j.electstud.2016.11.004

[II-2] O'Neill, Aaron. "Voter turnout in US presidential elections by ethnicity 1964-2016". Statistica. 30 July 2020.

https://www.statista.com/statistics/1096113/voter-turnout-presidential-elections-by-ethnicity-histo rical/

[II-3] Igielnik, Ruth. "Men and women in the U.S. continue to differ in voter turnout rate, party identification". Pew Research Center. 18 August 2020.

https://pewrsr.ch/3kUITya

[II-4] Bond, Robert M., Fariss, Christopher J., Jones, Jason J., et al. "A 61-million-person experiment in social influence and political mobilization.” Nature 489, 295-298 (2012). 12 September 2012. https://doi.org/10.1038/nature11421

[II-5] Stamp, Gavin. "Election: How do friends and family influence votes?" BBC News. 1 May 2020. http://news.bbc.co.uk/2/hi/uk_news/politics/election_2010/8622748.stm

[II-6] "New Census Bureau Estimates Show Counties in South and West Lead Nation in Population Growth.” United States Census Bureau, Release Number CB19-55. 18 April 2019.

https://www.census.gov/newsroom/press-releases/2019/estimates-county-metro.html

[II-7] "Reported Voting and Registration of Family Members, by Age and Family Income: November 2016.” United States Census Bureau, Release Number P20 Tables. May 2017.

https://www2.census.gov/programs-surveys/cps/tables/p20/580/table07.xlsx

[II-8] McCann, Adam. "Most \& Least Politically Engaged States.” WalletHub. 13 October 2020. https://wallethub.com/edu/most-least-politically-engaged-states/7782

[II-9] "Table A-2. Reported Voting and Registration by Region, Educational Attainment and Labor Force Status for the Population 18 and Over: November 1964 to 2018.” US Census Bureau.

https://www2.census.gov/programs-surveys/cps/tables/time-series/voting-historical-time-series/a2 .xlsx

[II-10] Parker, Kim. "The Growing Partisan Divide in Views of Higher Education”. Pew Research Center. 14 May 2020.

https://www.pewresearch.org/social-trends/2019/08/19/the-growing-partisan-divide-in-views-of-h igher-education-2/

[II-11] Desilver, Drew. "In past elections, U.S. trailed most developed countries in voter turnout". Pew Research Center. 3 November 2020. https://pewrsr.ch/2LjNokk

[II-12] Burden, Barry C., Canon, David T., Mayer, Kenneth R., Moynihan, Donald P. "Election Laws, Mobilization, and Turnout: The Unanticipated Consequences of Election Reform." American Journal of Political Science, Volume 58, Issue 1, Pages 95-109. 09 September 2013. https://doi.org/10.1111/ajps.12063 


\section{Supplementary Information}

Here is additional information not shown in the main paper: the quantitative analysis of youth voter impact in Section I, and the study for improving youth participation in Section II.

\section{THE QUANTITATIVE ANALYSIS OF YOUTH VOTER IMPACT}

Please contact the research and author of this paper for a copy of the research paper, "A Data-Driven Analysis of Youth Turnout Impact on U.S. Presidential Elections".

\section{THE STUDY FOR IMPROVING YOUTH PARTICIPATION}

Please contact the research and author of this paper for a copy of the research paper, "A Study for Improving Youth Voter Participation". 